Correction

\title{
Correction: Fudala, K. and Bialik, R.J. Breeding Colony Dynamics of Southern Elephant Seals at Patelnia Point, King George Island, Antarctica. Remote Sensing 2020, 12, 2964
}

\author{
Katarzyna Fudala 1,2 and Robert Józef Bialik ${ }^{1, * \mathbb{D}}$
}

1 Institute of Biochemistry and Biophysics, Polish Academy of Sciences, Pawińskiego 5A, 02-106 Warsaw, Poland; fudala.katarzyna@ibb.waw.pl

2 Faculty of Animal Breeding, Bioengineering and Conservation, Warsaw University of Life Sciences-SGGW, Nowoursynowska 166, 02-787 Warsaw, Poland

* Correspondence: rbialik@ibb.waw.pl

Received: 10 November 2020; Accepted: 11 November 2020; Published: 13 November 2020 updates

The authors wish to make the following correction to this paper [1].

In the original article, there was a mistake in the legend for Figure 7, which for the blue square, should be corrected as follows: "All pups at Patelnia Point". The correct figure appears below. The authors apologize for any inconvenience caused and state that the scientific conclusions are unaffected.

Replace

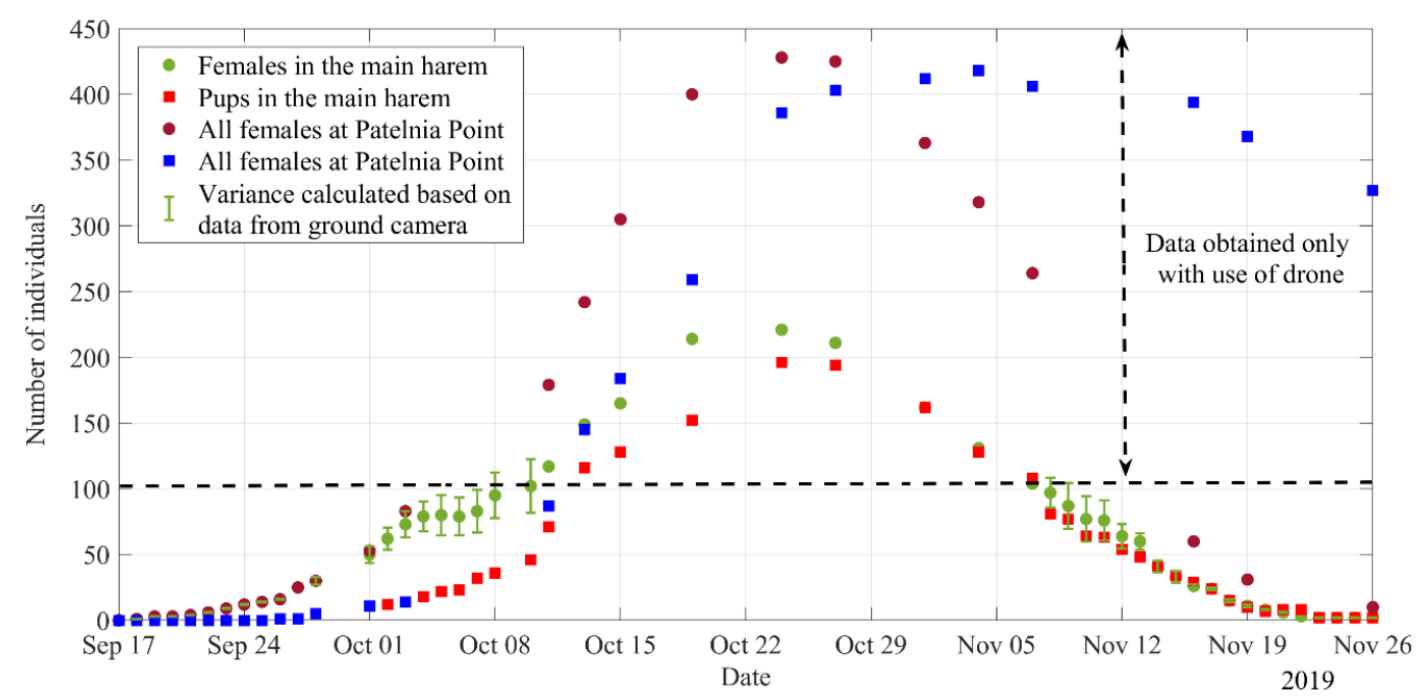

Figure 7. Number of females and pups in the entire area of Patelnia Point and in the main harem. 
with

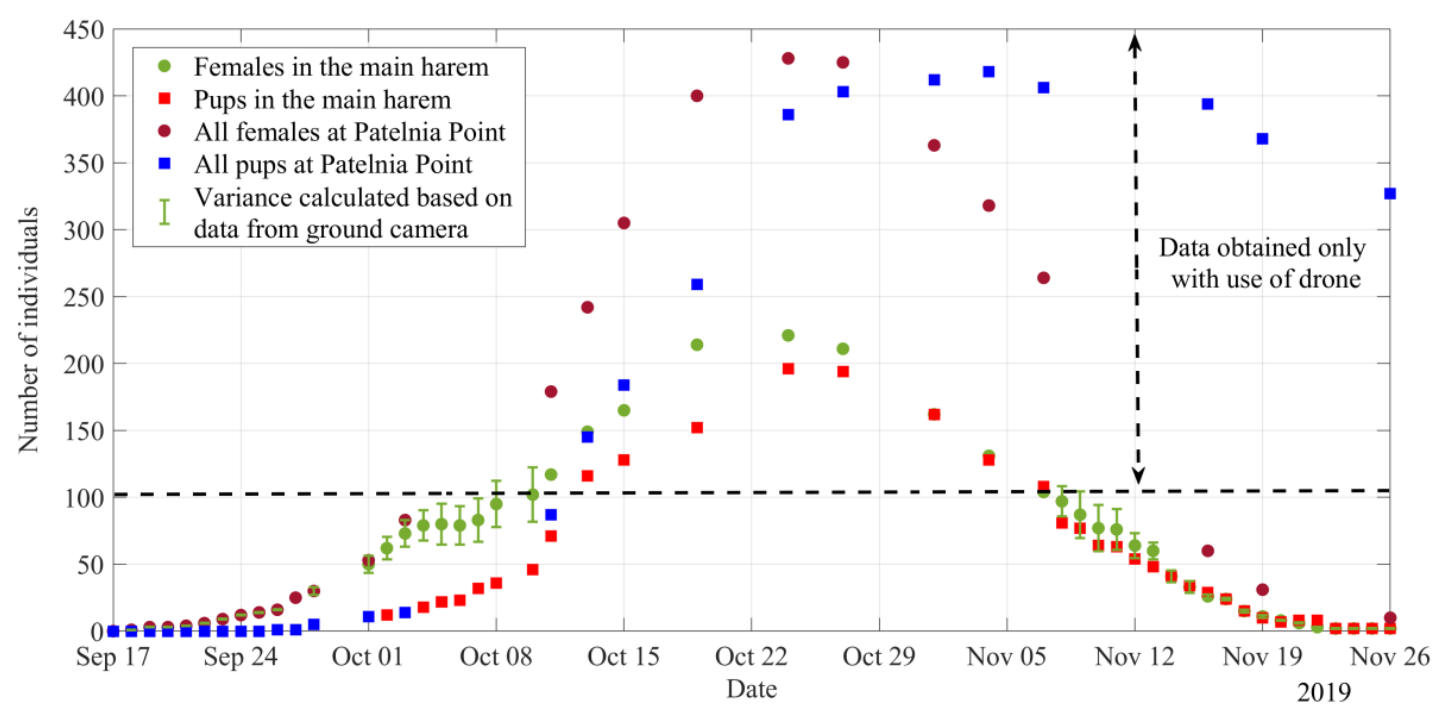

Figure 7. Number of females and pups in the entire area of Patelnia Point and in the main harem.

\section{Reference}

1. Fudala, K.; Bialik, R.J. Breeding Colony Dynamics of Southern Elephant Seals at Patelnia Point, King George Island, Antarctica. Remote Sens. 2020, 12, 2964. [CrossRef]

Publisher's Note: MDPI stays neutral with regard to jurisdictional claims in published maps and institutional affiliations.

(C) 2020 by the authors. Licensee MDPI, Basel, Switzerland. This article is an open access article distributed under the terms and conditions of the Creative Commons Attribution (CC BY) license (http://creativecommons.org/licenses/by/4.0/). 